\title{
Hyperaminoacidaemia at postprandial levels does not modulate glucose metabolism in type 2 diabetes mellitus
}

\author{
M. Bassil • S. Burgos • E. B. Marliss • J. A. Morais • \\ S. Chevalier • R. Gougeon
}

Received: 17 December 2010 / Accepted: 16 February 2011 /Published online: 25 March 2011

(C) Springer-Verlag 2011

\begin{abstract}
Aims/hypothesis Hyperaminoacidaemia attenuates glucose disposal during hyperinsulinaemic clamps in healthy lean individuals, an effect thought to be mediated by negative feedback on insulin signalling, downstream of the mammalian target of rapamycin (mTOR) signalling pathway. This has been interpreted as amino acids causing insulin resistance in healthy people, and contributing to it in type 2 diabetes. However, the effect of hyperaminoacidaemia on glucose disposal in type 2 diabetic individuals remains to be determined.

Methods Eight obese men with type 2 diabetes underwent a two-step hyperinsulinaemic-hyperglycaemic $(8 \mathrm{mmol} / \mathrm{l})$ clamp, first with amino acids at postabsorptive concentrations, followed by postprandial concentrations. Wholebody glucose turnover was assessed using D- $\left[3-{ }^{3} \mathrm{H}\right]$ glucose. Vastus lateralis biopsies were obtained at baseline and during each step of the clamp to determine the phosphorylation states of AKT, mTOR, ribosomal protein (rp) S6, and insulin receptor substrate (IRS)-1.

Results Rates of glucose infusion $(1.30 \pm 0.19$ vs $1.15 \pm$ $0.13 \mathrm{mmol} / \mathrm{min})$, endogenous glucose production $(0.48 \pm 0.06$ vs $0.53 \pm 0.05 \mathrm{mmol} / \mathrm{min})$ and disposal $(1.24 \pm 0.17$ vs $1.17 \pm$ $0.14 \mathrm{mmol} / \mathrm{min}$ ) did not differ between postabsorptive and postprandial amino acid concentrations $(p>0.05)$. Whereas phosphorylation of $\mathrm{AKT}^{\mathrm{Ser} 473}, \mathrm{AKT}^{\mathrm{Thr} 308} \mathrm{mTOR}^{\mathrm{Ser} 2448}$ and $\mathrm{rpS6}^{\mathrm{Ser} 235 / 236}$ increased $(p<0.05)$ with elevated amino acids, that of IRS-1 ${ }^{\text {Ser636/639 }}$ and IRS-1 ${ }^{\text {Ser1101 }}$ did not change.
\end{abstract}

M. Bassil · S. Burgos • E. B. Marliss • J. A. Morais

S. Chevalier $\cdot$ R. Gougeon $(\triangle)$

McGill Nutrition and Food Science Centre,

MUHC/Royal Victoria Hospital,

687 Pine Avenue West, H6.61,

Montreal, QC, Canada H3A 1A1

e-mail: rejeanne.gougeon@muhc.mcgill.ca
Conclusions/interpretation Postprandial circulating amino acid concentrations do not worsen the already attenuated glucose disposal in hyperglycaemic type 2 diabetic men, and cell-signalling events are consistent with this. Our results do not support recommendations to restrict dietary protein in type 2 diabetes.

Keywords Glucose disposal · Glucose metabolism .

Glucose turnover $\cdot$ Hyperaminoacidaemia .

Hyperinsulinaemic clamp · Insulin resistance .

Type 2 diabetes

$\begin{array}{ll}\text { Abbreviations } \\ \text { BCAA } & \text { Branched-chain amino acids } \\ \text { FFM } & \text { Fat-free mass } \\ \text { IRS } & \text { Insulin receptor substrate } \\ \text { isoAA } & \text { Isoaminoacidaemic } \\ \text { hyperAA } & \text { Hyperaminoacidaemic } \\ \text { MCR } & \text { Metabolic clearance rate } \\ \text { mTORC1 } & \text { Mammalian target of rapamycin complex 1 } \\ \text { NEFA } & \text { Non-esterified fatty acids } \\ R_{\mathrm{a}} & \text { Rate of appearance } \\ R_{\mathrm{d}} & \text { Rate of disappearance } \\ \text { rp } & \text { Ribosomal protein } \\ \text { S6K } & \text { S6 kinase } \\ \text { Ser } & \text { Serine } \\ \text { TBS-T } & \text { Tris-buffered saline containing 0.1\% Tween 20 } \\ \text { Thr } & \text { Threonine }\end{array}$

\section{Introduction}

Optimal protein intake in type 2 diabetes is not clearly defined. Evidence cited to recommend decreasing intake 
includes observational studies reporting that high protein consumption is associated with impaired glucose metabolism [1], risk of increasing insulin resistance and also precipitating type 2 diabetes [2-4]. Furthermore, amino acids blunt glucose uptake in vitro [5-7] and in healthy humans at the whole-body [8-12] and tissue levels [8, 13]. In healthy men, during hyperinsulinaemic-euglycaemic clamps, whole-body glucose uptake was lower when amino acids were infused to maintain basal $[8,14]$ or twice-basal plasma amino acid concentration [9, 10, 12, 14]. We have reported lower glucose metabolic clearance rate (MCR) in healthy men during hyperinsulinaemic clamps when glucose and amino acids were raised to postprandial concentrations compared with hyperinsulinaemic-euglycaemic clamps with amino acids maintained at fasting concentrations [11].

Findings from clamp studies in healthy participants were extrapolated to insulin-resistant states to postulate that increased protein intake in type 2 diabetes could contribute to peripheral insulin resistance of glucose metabolism [12]. Fasting branched-chain amino acids (BCAA) may be elevated in type 2 diabetes $[15,16]$ and were suggested to induce insulin resistance in a similar manner [12]. By contrast, short-term intervention studies have reported improved glycaemic control in type 2 diabetes with higher protein diets [17-20]. This was mainly attributed to proteininduced insulin secretion, which, unlike for glucose, appears to be preserved $[21,22]$ or even potentiated [23] in people with type 2 diabetes. It is still not clear whether hyperaminoacidaemia alters glucose disposal in that population, independently from its effect on insulin secretion.

Molecular mechanisms implicated in amino acidinduced insulin resistance of glucose disposal in skeletal muscle include activation of ribosomal protein (rp) S6 kinase 1 (S6K1) [24], a downstream effector of the mammalian target of the rapamycin complex 1 (mTORC1) signalling pathway [10], which phosphorylates the insulin receptor substrate (IRS)-1 at specific serine residues [9, 24]. This, in turn, inhibits IRS-1 function by reducing IRS-1associated phosphatidylinositol 3-kinase activity [6, 25] and deactivates downstream components of the insulin signalling cascade. This ultimately results in diminished translocation of GLUT-4 to the cell membrane and attenuated glucose uptake. Some of the multiple IRS-1 serine residues identified in humans, whose inhibitory phosphorylation is associated with mTOR/S6K1 activation, are Ser312, Ser636/639, and Ser1101.

The current protocol was designed to study hyperglycaemic men with type 2 diabetes during hyperinsulinaemic clamps and compare glucose turnover rates with amino acids clamped first at postabsorptive (isoaminoacidaemic, isoAA) concentration with those with amino acids raised to postprandial (hyperaminoacidaemic, hyperAA) concentra- tion. Muscle biopsies were obtained at baseline and at each step of the clamp for quantification of relevant intracellular signalling molecules.

\section{Methods}

Eight white obese men with type 2 diabetes, aged $<65$ years and conventionally treated, were studied. They were screened with fasting blood and urine samples, electrocardiogram, chest X-ray and a complete physical examination. Participants signed the study consent form approved by the institutional Human Ethics Review Board. Exclusion criteria included smoking, unstable weight for the previous 6 months, insulin therapy, abnormal dietary habits assessed by a $24 \mathrm{~h}$ recall, and any significant hepatic, haematological, renal, pulmonary, thyroid or cardiovascular dysfunction.

Participants were admitted for 4 days to the McGill University Health Centre/Royal Victoria Hospital Clinical Investigation Unit. All participants were taking oral antihyperglycaemic drugs: metformin (eight participants); sulfonylureas (six participants); and repaglinide (one participant). Five men were treated with statins and six with antihypertensive agents. All medications except antihypertensives were held on the clamp day until the end of the experiment. Each person consumed a formulabased (80\% Ensure and 20\% Glucerna; Abbott, Saint Laurent, QC, Canada) isoenergetic, protein-controlled diet for 6 days ( 3 days at home) to assure nitrogen balance at equilibrium before the clamp experiment. This provided $1.7 \mathrm{~g}$ protein ( $\mathrm{kg}$ fat-free mass [FFM] $)^{-1} \mathrm{day}^{-1}$ (16\% of energy), 59\% of energy from carbohydrates and $25 \%$ from fat. The calculated energy requirement for weight maintenance was based on resting metabolic rate by indirect calorimetry (Deltatrac; SensorMedics, Yorba Linda, CA, USA), multiplied by $\sim 1.6$. An energy supplement [2/3 glucose polymer (Polycose; Abbott) and $1 / 3$ vegetable oil] was given to correct for energy lost as the preceding day's measured glycosuria. Waist circumference was measured according to World Health Organization 1995 criteria [26]. Body composition was determined by bioimpedance analysis (RJL-101A Systems, Detroit, MI, USA) and dual-energy x-ray absorptiometry (Lunar Prodigy Advance; GE Healthcare, Madison, WI, USA). Any pre-meal capillary glucose (Accuchek III; Boehringer Ingelheim, Mannheim, Germany) $>15 \mathrm{mmol} / \mathrm{l}$ was treated by small doses of insulin, except during the $15 \mathrm{~h}$ before the clamp.

On the clamp day, at 08:00 h, with participants in the postabsorptive state, catheters were inserted in an antecubital vein for infusions, and in the opposite hand vein, which was kept in a heated box at $65-70^{\circ} \mathrm{C}$ to arterialise the venous blood for blood sampling. The protocol began 
20 min later. Glucose turnover was determined with a primed $(814 \mathrm{kBq})$ continuous $(8.14 \mathrm{kBq} / \mathrm{min})$ infusion of D- $\left[3-{ }^{3} \mathrm{H}\right]$ glucose (PerkinElmer, Boston, MA, USA). Concurrently, a primed infusion of regular human insulin $\left(0.95 \mathrm{mU}[\mathrm{kg} \mathrm{FFM}]^{-1} \mathrm{~min}^{-1}\right.$ ) (Humulin R; Eli Lilly Canada, Toronto, ON, Canada) was started. Glucose $(20 \%)$ in water (Avebe, Foxhol, the Netherlands) and a 10\% amino acid solution (TrophAmine 10\% without electrolytes, B. Braun Medical, Irvine, CA, USA) were infused to maintain concentrations at $8 \mathrm{mmol} / \mathrm{l}$ for glucose and at each individual's fasting BCAA concentrations, based on arterialised venous concentration measurements made every 5-10 min. Three hours after the start of insulin, BCAA levels were increased to, and maintained at $\sim 750 \mu \mathrm{mol} / 1$ to match peak postprandial concentrations reached during a meal test $(2,981 \mathrm{~kJ}, 30 \mathrm{~g}$ protein) done in lean, healthy participants (data not shown). The intravenous insulin infusion was decreased by $17 \%$ to adjust for the stimulation of endogenous insulin secretion from increasing amino acid concentrations [21]. The hyperAA clamp lasted for an additional $3 \mathrm{~h}$, after which all infusions were stopped. Steady states of glucose and amino acid concentrations and infusion rates were achieved within $120 \mathrm{~min}$ and maintained until $180 \mathrm{~min}$ at each step of the clamps. Glucose turnover was calculated during the last $30 \mathrm{~min}$ ('plateau') of each step. Indirect calorimetry was performed for $20 \mathrm{~min}$ at baseline and during both plateaus. Blood samples for substrates, hormones and glucose turnover measurements were collected at baseline every hour until $50 \mathrm{~min}$ before the end of each step and at 10 min intervals thereafter. At baseline and $2 \mathrm{~h}$ after the start of each step, $\sim 100 \mathrm{mg}$ vastus lateralis muscle biopsies were obtained with a Bergström needle under anaesthesia (2\% Xylocaine; Astra-Zeneca Canada, Mississauga, ON, Canada) using sterile techniques and immediately frozen in liquid nitrogen.

Assays Plasma glucose concentration was measured by glucose oxidase (GM7 Micro-Stat; Analox Instruments USA, Lunenberg, MA, USA), and BCAA by an enzymatic, fluorometric assay (FP-6200; Jasco Corporation, Tokyo, Japan) [27]. Serum insulin, C-peptide and glucagon were determined by RIA (Millipore, Billerica, MA, USA) [28]. Glucose turnover was calculated with OOPSEG [29]. Nonesterified fatty acids (NEFA) were measured by a colorimetric assay (NEFA C; Wako Chemicals USA, Richmond, VA, USA) and reverse-phase HPLC was used to determine individual plasma amino acid concentrations after precolumn derivatisation with $o$-phtalaldehyde [30].

Analysis of phosphorylation state of signalling proteins Muscle samples (25 mg wet weight) were homogenised on ice for $30 \mathrm{~s}$ in 10 volumes of homogenisation buffer (final concentration: 20 mmol/1 HEPES, pH 7.4, 2 mmol/l EGTA,
$50 \mathrm{mmol} / 1 \mathrm{NaF}, 100 \mathrm{mmol} / 1 \mathrm{KCl}, 0.2 \mathrm{mmol} / 1 \mathrm{EDTA}$, $10 \mathrm{mmol} / 1 \mathrm{Na}_{4} \mathrm{PO}_{7}, 50 \mathrm{mmol} / 1 \quad \beta$-glycerophosphate) supplemented with $0.5 \mathrm{mmol} / 1 \mathrm{Na}_{3} \mathrm{VO}_{4}, 1 \mu \mathrm{mol} / 1$ microcystin LR, $1 \mathrm{mmol} / 1$ dithiothreitol, $1 \mathrm{mmol} / 1$ phenylmethylsulfonyl fluoride and $10 \mu \mathrm{g} / \mathrm{ml}$ each of aprotinin, leupeptin and pepstatin using a hand-held homogeniser (Tissuemiser; Fisher Scientific, Mississauga, ON, Canada). The homogenate was cleared by centrifugation at $15,000 \mathrm{~g}$, at $4^{\circ} \mathrm{C}$, for $15 \mathrm{~min}$. A portion of the homogenate was used to measure protein concentration by the Bradford method (Bio-Rad Laboratories, Hercules, CA, USA) using BSA as standard [31]. A portion of the remaining supernatant fraction was mixed with an equal volume of $2 \times$ Laemli sample buffer and then boiled for $5 \mathrm{~min}$. Samples ( $25 \mu \mathrm{g}$ of protein/lane) were resolved by SDS-PAGE and then transferred onto polyvinylidine fluoride membranes (GE Healthcare). The membranes were blocked in 5\% non-fat dried milk in Tris-buffered saline containing $0.1 \%$ Tween 20 (TBS-T) at room temperature for $1 \mathrm{~h}$ and then incubated with phospho-specific primary antibodies against AKT (Thr308), AKT (Ser473), IRS-1 (Ser1101) and (Ser636/639), mTOR (Ser2448) and rpS6 (Ser235/ 236) at $4^{\circ} \mathrm{C}$ overnight. Membranes were washed three times for $5 \mathrm{~min}$ in TBS-T and subsequently incubated with secondary antibody in TBS-T containing 5\% non-fat dried milk at room temperature for $1 \mathrm{~h}$. Immunoblots were developed by enhanced chemiluminescence using ChemiDOC XRS Multi-Imager system (Bio-Rad Laboratories). After detection of the phospho-specific signal, the antibodies were stripped off the membrane by incubation in $62.5 \mathrm{mmol} / 1 \mathrm{Tris}-\mathrm{HCl}, 100 \mathrm{mmol} / \mathrm{l} \beta$-mercaptoethanol, and $2 \% \mathrm{SDS}$ at $50^{\circ} \mathrm{C}$ for $30 \mathrm{~min}$. The membranes were then washed, blocked and reprobed with primary antibodies against total AKT, IRS-1, mTOR and rpS6. All antibodies were from Cell Signaling Technology (Danvers, MA, USA). Results are expressed as ratios of phosphorylated to total protein.

Statistical analysis Results are presented as mean \pm SEM. The effects of the three metabolic states (baseline vs isoAA vs hyperAA) were compared by repeated measures of analysis of variance (ANOVA) and least significant difference (LSD) post-hoc test, or paired $t$ test (isoAA vs hyperAA) [SPSS 17.0 for Windows (SPSS, Chicago, IL, USA)]. Based on a crossover design [32] and SD [12], eight individuals were sufficient to detect a $25 \%$ difference in glucose disposal between isoAA and hyperAA (twotailed $\alpha=0.05, \beta=0.95$ ).

\section{Results}

Of the eight men, one was overweight and the rest were obese (Table 1). Adiposity markers (BMI, per cent body fat 
Table 1 Participant characteristics

\begin{tabular}{lc}
\hline Characteristic & Value \\
\hline Age (years) & $57 \pm 2$ \\
Height (cm) & $177.5 \pm 2.1$ \\
Weight $(\mathrm{kg})$ & $107.7 \pm 7.3$ \\
BMI $\left(\mathrm{kg} / \mathrm{m}^{2}\right)$ & $34.0 \pm 1.6$ \\
FFM $(\mathrm{kg})$ & $69.6 \pm 4.1$ \\
Body fat $(\%)$ & $34.9 \pm 2.2$ \\
Waist circumference (cm) & $118.6 \pm 4.8$ \\
HOMA-IR & $11.51 \pm 2.53$ \\
Diabetes duration (years) & $9 \pm 2$ \\
\hline
\end{tabular}

Data are mean \pm SEM and waist circumference) were above reference values [26], and according to the HOMA index, all were insulin resistant [33]. Plasma glucose and BCAA concentrations and infusion rates during the clamp are presented in Fig. 1. Participants were hyperglycaemic at baseline (time 0) and plasma glucose was maintained at $8 \mathrm{mmol} / \mathrm{l}$ for the duration of the clamp. Fasting BCAA by HPLC $(454 \pm 23 \mu \mathrm{mol} / \mathrm{l})$ were clamped during isoAA then raised and maintained at postprandial concentrations $(780 \pm 24 \mu \mathrm{mol} / \mathrm{l})$ during hyperAA. NEFA and hormone concentrations are presented in Fig. 2. During isoAA, insulin increased from $187 \pm 40$ $\mathrm{pmol} / \mathrm{l}$ to a typical postmeal concentration $(630 \pm 68 \mathrm{pmol} / \mathrm{l})$ that was maintained during hyperAA $(659 \pm 71 \mathrm{pmol} / \mathrm{l})$ by design, despite a $12 \%$ increase in C-peptide $(p=0.049)$. Plasma glucagon concentration decreased from baseline
Fig. 1 Glucose (a) and amino acid (b) concentrations (black squares) and infusion rates (black diamonds) during isoAA vs hyperAA phases of the clamp in men with type 2 diabetes. $* p<0.05$ vs isoAA a

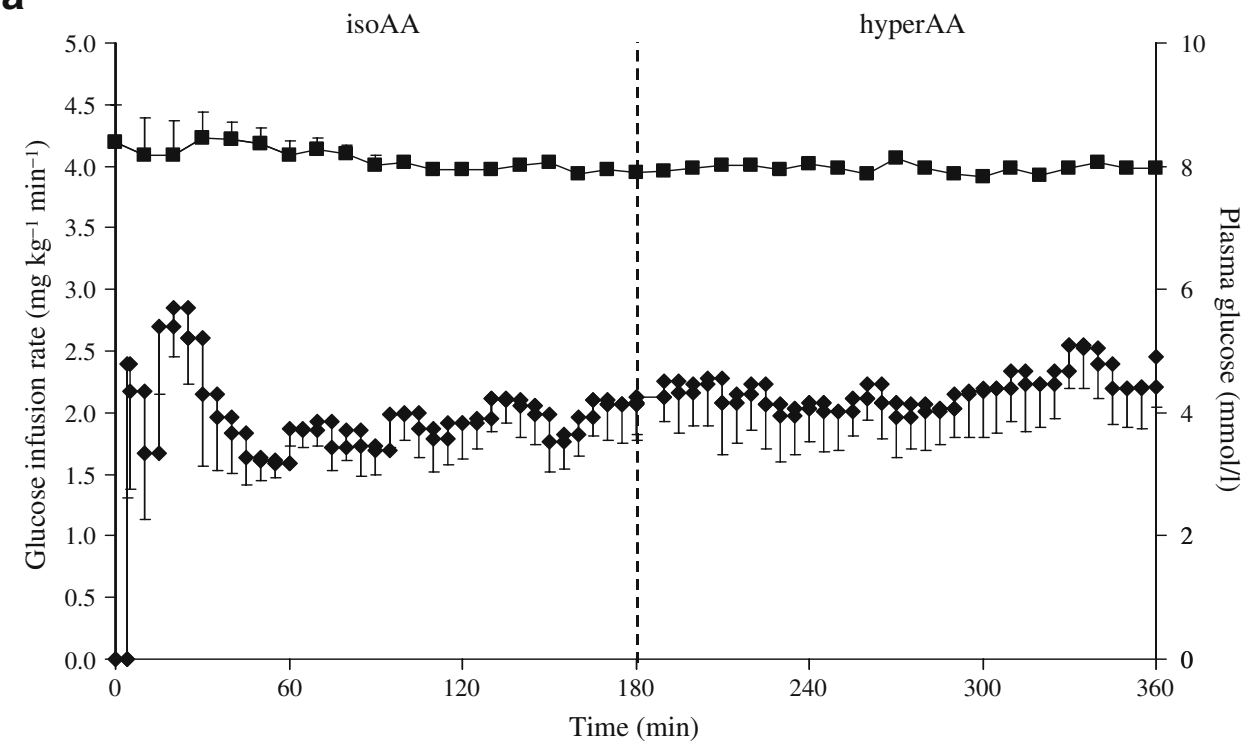

b

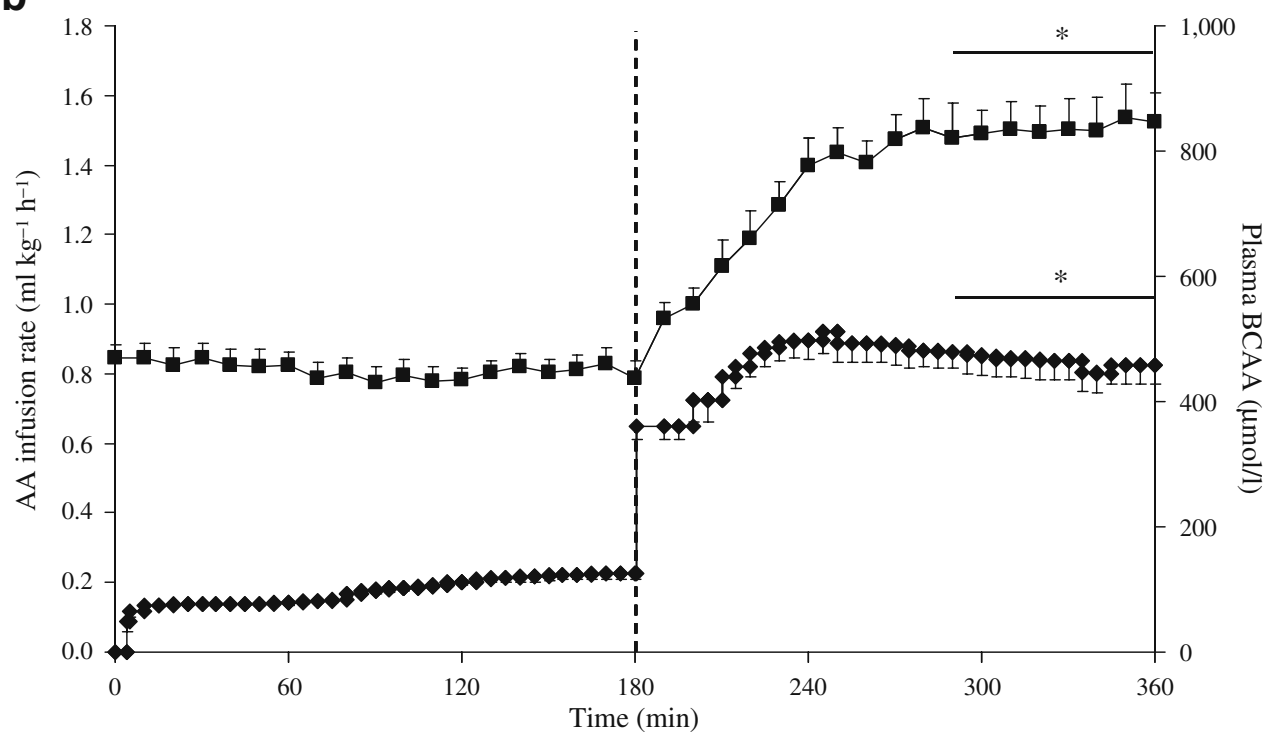


a
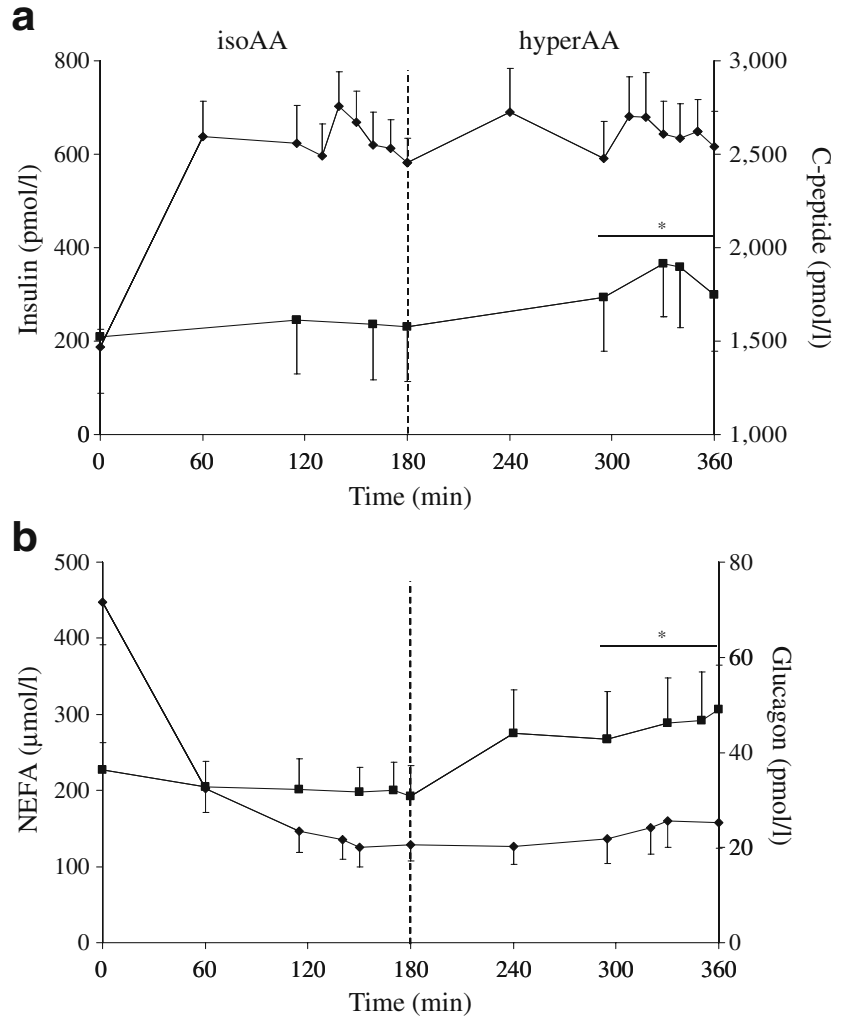

Fig. 2 Hormone and NEFA concentrations at baseline and during isoAA and hyperAA phases of the clamp in men with type 2 diabetes. (a) Insulin (black diamonds) and C-peptide (black squares) concentrations. ${ }^{*} p<0.05$ vs isoAA. (b) Glucagon (black squares) and NEFA (black diamonds) concentrations. ${ }^{*} p<0.05$ vs isoAA

during isoAA $(p=0.008)$ and then increased by $45 \%$ during hyperAA. NEFA were suppressed to the same extent in both steps of the clamp.

Baseline and clamp plasma amino acid concentrations are shown in Table 2. Most amino acids, as well as the total, were maintained at their baseline concentrations during isoAA. There was a slight but significant increase in leucine and arginine concentrations by $22 \%$ and $14 \%$, respectively, and an $18 \%$ decrease in tyrosine concentration. During hyperAA, concentrations of all amino acids except tyrosine and asparagine were higher such that total amino acids were increased by $34 \%$.

Rates of endogenous glucose production (endogenous rate of appearance $\left[R_{\mathrm{a}}\right]$ ), glucose infusion and the total, oxidative and non-oxidative glucose disposal (rate of disappearance $\left[R_{\mathrm{d}}\right]$ ) during hyperAA did not differ from those of isoAA (Table 3 ).

In the muscle biopsies (Fig. 3a-e), during isoAA, there was a significant increase from baseline in the phosphorylation of AKT at Ser473 $(p=0.002)$ and Thr308 $(p=0.001)$, mTOR $(p=0.002)$ and $\operatorname{rpS6}(p=0.035)$. During hyperAA, AKT phosphorylation at Thr308 and Ser473 decreased but remained $87 \%(p=0.09)$ and $74 \%(p=0.029)$ higher than baseline, respectively. Hyperaminoacidaemia was associated with an additional 57\% increment in mTOR phosphorylation compared with isoAA. rpS6 phosphorylation remained significantly higher than baseline during hyperAA $(p=0.004)$. Importantly, IRS-1 phosphorylation at Ser636/639 and Ser1101 did not differ across the three time points (Fig. 3d,e).

\section{Discussion}

The present study shows that, unlike that previously shown in healthy lean individuals, increasing plasma amino acids does not lower the already blunted glucose disposal in men with type 2 diabetes in hyperinsulinaemic-hyperglycaemic conditions. Such conditions prevail postprandially in a large proportion of people with conventionally treated type 2 diabetes. The study was designed to test the effect of one variable, postprandial-level hyperaminoacidaemia on glucose turnover during hyperAA, while maintaining the other two conditions constant compared with isoAA. Therefore, branched-chain and total amino acids were raised to peak concentrations observed after a mixed meal in healthy lean participants. Insulin was clamped at the postprandial peripheral venous concentration we have found in type 2 diabetes [34], and was maintained unchanged during hyperAA, because we decreased the insulin infusion rate. This compensated for amino acid stimulation of endogenous insulin secretion, as inferred from the C-peptide rise. However, this infers higher portal vein insulin concentration. Although glucagon was slightly increased by amino acids during hyperAA, it did not affect endogenous glucose production compared with isoAA (Table 3). This could be because of the higher portal insulin overriding any effect glucagon might have on endogenous $R_{\mathrm{a}}$. In addition, with insulin being 3.5 -fold higher, the glucagon to insulin ratio was minimally altered $(0.07 \pm 0.01$ vs $0.05 \pm 0.01$ in isoAA). Insofar as NEFA might play a role in postprandial insulin resistance in type 2 diabetes, in the present case this potential effect appears to be minimal, as NEFA were suppressed to identical concentrations in both phases of the clamp.

The whole-body glucose $R_{\mathrm{d}}$ did not change despite doubling of BCAA and leucine concentrations vs baseline during hyperAA. This, therefore, does not support the proposition that postprandial-level hyperaminoacidaemia worsens insulin resistance of glucose metabolism in type 2 diabetes, an effect that had been extrapolated from findings in lean healthy participants $[9,10,12]$ of a clamp protocol analogous to ours. These healthy individuals were studied during hyperinsulinaemic-euglycaemic pancreatic clamps, first without then with amino acids infused to reach and maintain hyperaminoacidaemia. The hyperaminoacidaemic 
Table 2 Plasma concentrations $(\mu \mathrm{mol} / \mathrm{l})$ of individual and total amino acids at baseline and during the clamp steady states
Data are mean \pm SEM

${ }^{\text {a }}$ Not present in the infused amino acid formulation. Tyrosine is present as $N$-acetyl-L-tyrosine ${ }^{*} p<0.05$ vs baseline. ${ }^{\dagger} p<0.05$ vs isoAA

\begin{tabular}{|c|c|c|c|}
\hline Amino acids & Baseline & isoAA & hyperAA \\
\hline Essential amino acids & $966 \pm 51$ & $1,013 \pm 49$ & $1,547 \pm 66^{* \dagger}$ \\
\hline Histidine & $83 \pm 5$ & $95 \pm 5$ & $131 \pm 8^{* \dagger}$ \\
\hline Isoleucine & $70 \pm 5$ & $73 \pm 4$ & $162 \pm 7^{* \dagger}$ \\
\hline Leucine & $137 \pm 11$ & $156 \pm 8^{*}$ & $312 \pm 14 * \dagger$ \\
\hline Lysine & $181 \pm 15$ & $199 \pm 18$ & $277 \pm 19^{* \dagger}$ \\
\hline Methionine & $28 \pm 3$ & $30 \pm 2$ & $57 \pm 3 *^{\dagger}$ \\
\hline Phenylalanine & $63 \pm 4$ & $65 \pm 3$ & $94 \pm 8^{* \dagger}$ \\
\hline Threonine & $99 \pm 8$ & $94 \pm 8$ & $130 \pm 10^{* \dagger}$ \\
\hline Tryptophan & $58 \pm 4$ & $61 \pm 4$ & $84 \pm 5^{* \dagger}$ \\
\hline Valine & $248 \pm 7$ & $241 \pm 7$ & $301 \pm 12 *^{\dagger}$ \\
\hline Non-essential amino acids & $1,507 \pm 64$ & $1,519 \pm 104$ & $1,833 \pm 130 *$ \\
\hline Alanine & $290 \pm 7$ & $285 \pm 9$ & $296 \pm 10^{\dagger}$ \\
\hline Arginine & $76 \pm 6$ & $93 \pm 6^{*}$ & $182 \pm 10^{* \dagger}$ \\
\hline Asparagine $^{a}$ & $46 \pm 3$ & $41 \pm 5$ & $34 \pm 5^{* \dagger}$ \\
\hline Aspartic acid & $26 \pm 6$ & $33 \pm 8$ & $49 \pm 11 *^{\dagger}$ \\
\hline Citrulline & $39 \pm 2$ & $37 \pm 4$ & $50 \pm 5^{\dagger}$ \\
\hline Glutamine $^{\mathrm{a}}$ & $482 \pm 23$ & $461 \pm 29$ & $483 \pm 28$ \\
\hline Glutamic acid & $90 \pm 9$ & $107 \pm 9$ & $135 \pm 12^{* \dagger}$ \\
\hline Glycine & $173 \pm 15$ & $177 \pm 20$ & $200 \pm 23^{\dagger}$ \\
\hline Ornithine $^{\mathrm{a}}$ & $83 \pm 13$ & $96 \pm 20$ & $147 \pm 29^{\dagger}$ \\
\hline Serine & $89 \pm 11$ & $99 \pm 10$ & $126 \pm 12^{\dagger}$ \\
\hline Taurine $^{\mathrm{a}}$ & $43 \pm 5$ & $44 \pm 5$ & $53 \pm 5 * \dagger$ \\
\hline Tyrosine & $96 \pm 5$ & $79 \pm 5^{*}$ & $79 \pm 4 *$ \\
\hline Total amino acids & $2,473 \pm 99$ & $2,532 \pm 137$ & $3,381 \pm 182 *$ \\
\hline
\end{tabular}

phase of the clamp was associated with lowered glucose uptake. Our results also contrast with what we found previously in healthy lean men who had lower glucose MCR during hyperAA compared with a matched group studied during a hyperinsulinaemic-euglycaemic-isoaminoacidaemic clamp (euglycaemic isoAA) [11]. Glucose turnover rates from those studies are presented in Fig. 4: Nine healthy men (BMI $21.3 \pm 0.4 \mathrm{~kg} / \mathrm{m}^{2}$; age $26 \pm 1$ years; and FFM $59 \pm 1 \mathrm{~kg}$, all $p<0.05$ vs type 2 diabetic men) underwent a euglycaemic isoAA protocol with insulin $(449 \pm$ $24 \mathrm{pmol} / \mathrm{l})$, glucose $(5.50 \pm 0.01 \mathrm{mmol} / \mathrm{l})$ and BCAA (412 \pm $14 \mu \mathrm{mol} / \mathrm{l})$ clamped at lower concentrations $(p<0.05)$ than those of type 2 diabetic men during isoAA. Another group of eight healthy men (BMI $21.5 \pm 0.6 \mathrm{~kg} / \mathrm{m}^{2}$; age $29 \pm 3$ years;

Table 3 Clamp glucose kinetics

\begin{tabular}{lll}
\hline Kinetic rate & isoAA $(\mathrm{mmol} / \mathrm{min})$ & hyperAA $(\mathrm{mmol} / \mathrm{min})$ \\
\hline Endogenous $R_{\mathrm{a}}$ & $0.53 \pm 0.05$ & $0.48 \pm 0.06$ \\
Infusion rate & $1.15 \pm 0.13$ & $1.34 \pm 0.18$ \\
Total $R_{\mathrm{d}}$ & $1.68 \pm 0.11$ & $1.82 \pm 0.15$ \\
Oxidative $R_{\mathrm{d}}$ & $0.52 \pm 0.10$ & $0.58 \pm 0.12$ \\
Non-oxidative $R_{\mathrm{d}}$ & $1.17 \pm 0.14$ & $1.24 \pm 0.17$ \\
\hline
\end{tabular}

Data are mean \pm SEM and FFM 59 $\pm 2 \mathrm{~kg}$; all $p<0.05$ vs type 2 diabetic men) underwent a hyperAA protocol with glucose and amino acid concentrations similar to our study but with greater hyperinsulinaemia $(788 \pm 83 \mathrm{pmol} / \mathrm{l})$ as a result of a larger C-peptide response. Postprandial hyperinsulinaemia did not completely suppress endogenous $R_{\mathrm{a}}$ in diabetes in either clamp phase, as it did in lean non-diabetic participants (Fig. 4), despite lesser hyperinsulinaemia in the euglycaemic isoAA participants. This confirms hepatic insulin resistance in type 2 diabetes. Whole-body $R_{\mathrm{d}}$ in non-diabetic hyperAA did not differ from that of isoAA despite their higher glucose and insulin concentrations. Therefore, glucose MCR was significantly lower in non-diabetic hyperAA, suggesting that hyperaminoacidaemia impeded glucose disposal. By contrast, glucose $R_{\mathrm{d}}$ and MCR in type 2 diabetic men did not decrease from isoAA to hyperAA.

We postulate that hyperaminoacidaemia does not further impede glucose disposal in diabetes because glucose $R_{\mathrm{d}}$ and MCR are already markedly low compared with nondiabetic groups (Fig. 4), such that it is unlikely for hyperaminoacidaemia to have a further notable suppressive effect. Abnormalities in serine phosphorylation of IRS-1 associated with impaired insulin signalling are already established in diabetes [35-37]. Thus any additional perturbation via amino acid signalling might not add to 
a

b
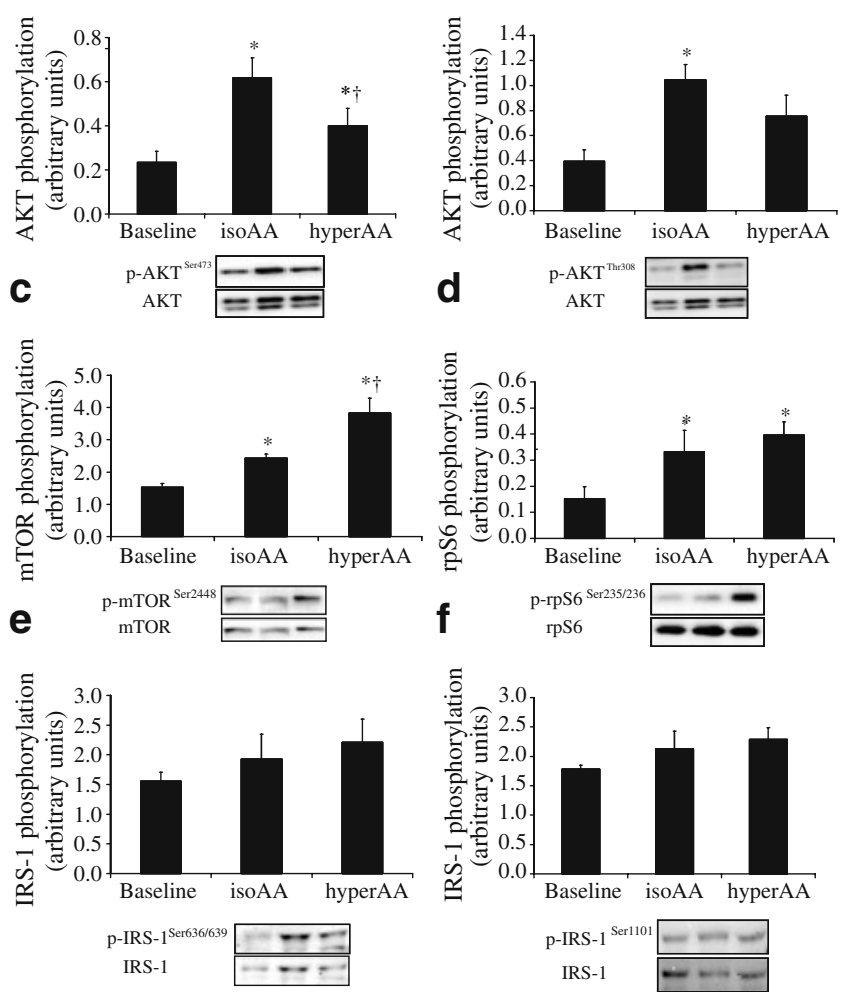

Fig. 3 Phosphorylation of AKT at Ser473 (a) and Thr308 (b), mTOR (c), rpS6 (d), IRS-1 at Ser636/639 (e) and Ser1101 (f) at baseline and during isoAA and hyperAA. Data are expressed as the ratio of phosphorylated to total protein. Representative western blots are shown. ${ }^{*} p<0.05$ vs baseline, ${ }^{\dagger} p<0.05$ vs isoAA

the degree and/or patterns of IRS-1 serine phosphorylation to further reduce glucose uptake. The data from muscle biopsies of the present study (Fig. 3) support this. Both

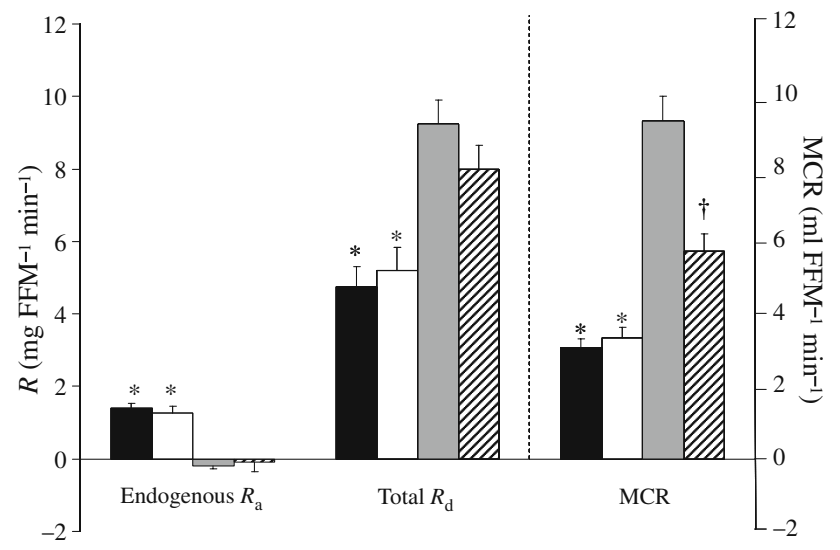

Fig. 4 Rates of endogenous glucose production $\left(R_{\mathrm{a}}\right)$, glucose disposal $\left(R_{\mathrm{d}}\right)$ and glucose MCR presented per $\mathrm{kg}$ FFM in men with type 2 diabetes during isoAA (black bar) and hyperAA (white bar), and in lean non-diabetic men during euglycaemic isoAA (grey bar) and hyperAA (hashed bar) (adapted from Adegoke et al. [Am J Physiol Endocrinol Metab, 2009] [11] with copyright permission from the American Physiological Society). $* p<0.05$ vs lean non-diabetic euglycaemic isoAA and hyperAA; ${ }^{\dagger}$ vs lean non-diabetic hyperAA
Ser1101 [24] and 636/639 [7] are sites implicated in the amino acid-induced negative feedback phosphorylation of IRS-1 through mTOR activation and the subsequent blunting of glucose disposal in healthy lean men. Whereas the sum of insulin and hyperaminoacidaemia caused increased phosphorylation of mTOR and downstream to rpS6 in hyperAA, IRS-1 Ser phosphorylation on both sites did not change, suggesting that it might already be stoichiometrically phosphorylated. Although our protocol lacked a healthy control group, Bouzakri et al. [38] have found more than twofold higher basal IRS-1 Ser $^{636}$ phosphorylation in a primary culture of skeletal muscle from diabetic participants compared with cells from healthy controls. Furthermore, Tremblay and colleagues [9] have reported that, although baseline state of IRS-1 serine phosphorylation on Ser312 and Ser636/639 was barely detectable, co-infusion of insulin and amino acids increased IRS-1 Ser636/639 phosphorylation by sixfold in lean healthy men. In our study, baseline phosphorylation of IRS-1 on both Ser1101 and Ser636/639 was detectable but did not change significantly with hyperinsulinaemia and hyperaminoacidaemia. Taken together, these data support our hypothesis that, unlike healthy individuals, there is an elevated baseline IRS-1 serine phosphorylation associated with reduced peripheral glucose uptake in type 2 diabetes and that acute elevation of amino acids does not further impair whole-body glucose $R_{\mathrm{d}}$ in hyperglycaemic type 2 diabetic men.

Although hyperinsulinaemia stimulated AKT phosphorylation during isoAA at Thr308 and Ser473 (Fig. 3a,b), increasing amino acids simultaneously during hyperAA was associated with a lower AKT phosphorylation at both sites. This could be because of time-dependent desensitisation of insulin signalling as the muscle biopsy during hyperAA was obtained $5 \mathrm{~h}$ after the start of insulin infusion. This could also be attributed to a negative feedback loop by mTORC1 through a mechanism not involving IRS-1 as reviewed by Hay [39].

Several aspects of our study influence interpretation of the results and comparison with studies performed in healthy lean men $[9,10,12]$. First, the hyperAA steadystate does not mimic the temporal non-steady state changes in substrate and hormone concentrations that occur during meal absorption. Thus, it remains to be shown whether similar findings, or magnitude of effects, would be seen with oral feeding. Second, isoAA preceded hyperAA and thus the time of exposure to exogenous insulin and amino acids may have influenced the response to the second phase, including the phosphorylation state of molecules in the muscle intracellular signalling pathways. Third, serum insulin concentration was a combination of both endogenous and exogenous sources and the proportions differed in the two phases of the clamp. This is in 
contrast to clamp studies $[9,10,12]$ in which somatostatin was infused, so circulating insulin and glucagon were most probably exogenous. Fourth, we maintained fasting amino acid concentrations during isoAA by exogenous amino acid infusion, unlike other studies $[9,10,12]$ in which amino acids were not infused during the first hyperinsulinaemic clamp. Hence, plasma amino acid concentrations dropped below fasting levels. Furthermore, during hyperinsulinaemic-euglycaemic clamps, merely infusing amino acids to maintain plasma concentrations close to baseline (vs no infusion) decreased glucose uptake [8]. Therefore, it is possible that by lowering the amino acid concentrations, there is some release of the negative feedback signal that would improve glucose uptake. Last, although BCAA levels in the studies by others $[9,10,12]$ were comparable to those achieved during our hyperAA, other individual as well as total amino acids $(6,000 \mu \mathrm{mol} / 1$ in $[9,10,12]$ vs $3,381 \mu \mathrm{mol} / 1$ in the present study) were markedly higher. This is as a result of the lower BCAA proportion of the total amino acids in solutions used in those studies. Individual amino acids, other than leucine, were found to suppress glucose transport in L6 myotubes [6]. It is therefore difficult to exclude whether the supraphysiological increases in some amino acids in these studies $[9,10,12]$ would contribute to the blunted glucose uptake. This effect, if present, would be less in our study. We selected the specific commercial amino acid solution TrophAmine (B. Braun Medical), because it is particularly rich in leucine, the other BCAA, and essential amino acids, as well as arginine. This probably contributed to the significant increase in leucine and arginine in isoAA (Table 2). TrophAmine (B. Braun Medical) induced protein anabolism in our previous clamp studies [11, 30, 40], while maintaining physiologically relevant levels of other amino acids.

In conclusion, we have demonstrated that abnormal glucose turnover is not aggravated by postprandial hyperaminoacidaemia in hyperglycaemic type 2 diabetic men. These findings, together with the evidence of impaired protein metabolism in diabetes [16] that is overcome by generous protein provision [41], do not support recommendations to restrict protein intake.

Acknowledgements This work was supported by a grant from Canadian Institutes of Health Research to R. Gougeon (MOP-77562) and salary awards to R. Gougeon and M. Bassil from the McGill University Health Centre Research Institute, and to S. Chevalier and J. A. Morais from 'Fonds de recherche en santé du Québec'. We thank M. Shingler, C. Légaré, J. Plescia, K. French, I. Lalonde, M. Lamarche, D. White, G. Sabourin, C. Nardolillo, and D. Brunetti for their assistance.

Duality of interest The authors declare that there is no duality of interest associated with this manuscript.

\section{References}

1. Skilton MR, Laville M, Cust AE, Moulin P, Bonnet F (2008) The association between dietary macronutrient intake and the prevalence of the metabolic syndrome. Br J Nutr 100:400-407

2. Schulze MB, Manson JE, Willett WC, Hu FB (2003) Processed meat intake and incidence of type 2 diabetes in younger and middle-aged women. Diabetologia 46:1465-1473

3. Liese AD, Weis KE, Schulz M, Tooze JA (2009) Food intake patterns associated with incident type 2 diabetes: the Insulin Resistance Atherosclerosis Study. Diab Care 32:263-268

4. Promintzer M, Krebs M (2006) Effects of dietary protein on glucose homeostasis. Curr Opin Clin Nutr Metab Care 9:463-468

5. Traxinger RR, Marshall S (1989) Role of amino acids in modulating glucose-induced desensitization of the glucose transport system. J Biol Chem 264:20910-20916

6. Tremblay F, Marette A (2001) Amino acid and insulin signaling via the mTOR/p70 S6 kinase pathway. J Biol Chem 276:3805238060

7. Tremblay F, Gagnon A, Veilleux A, Sorisky A, Marette A (2005) Activation of the mammalian target of rapamycin pathway acutely inhibits insulin signaling to Akt and glucose transport in 3T3-L1 and human adipocytes. Endocrinology 146:1328-1337

8. Pisters PW, Restifo NP, Cersosimo E, Brennan MF (1991) The effects of euglycemic hyperinsulinemia and amino acid infusion on regional and whole body glucose disposal in man. Metabolism 40:59-65

9. Tremblay F, Krebs M, Dombrowski L et al (2005) Overactivation of S6 kinase 1 as a cause of human insulin resistance during increased amino acid availability. Diabetes $54: 2674-2684$

10. Krebs M, Brunmair B, Brehm A et al (2007) The mammalian target of rapamycin pathway regulates nutrient-sensitive glucose uptake in man. Diabetes 56:1600-1607

11. Adegoke OAJ, Chevalier S, Morais JA et al (2009) Fed-state clamp stimulates cellular mechanisms of muscle protein anabolism and modulates glucose disposal in normal men. Am J Physiol Endocrinol Metab 296:E105-113

12. Krebs M, Krssak M, Bernroider E et al (2002) Mechanism of amino acid-induced skeletal muscle insulin resistance in humans. Diabetes 51:599-605

13. Schwenk WF, Haymond MW (1987) Decreased uptake of glucose by human forearm during infusion of leucine, isoleucine, or threonine. Diabetes 36:199-204

14. Flakoll PJ, Wentzel LS, Rice DE, Hill JO, Abumrad NN (1992) Short-term regulation of insulin-mediated glucose utilization in four-day fasted human volunteers: role of amino acid availability. Diabetologia 35:357-366

15. Felig P, Marliss E, Ohman JL, Cahill GF Jr (1970) Plasma amino acid levels in diabetic ketoacidosis. Diabetes 19:727-728

16. Pereira S, Marliss EB, Morais JA, Chevalier S, Gougeon R (2008) Insulin resistance of protein metabolism in type 2 diabetes. Diabetes 57:56-63

17. Gannon MC, Nuttall FQ (2004) Effect of a high-protein, lowcarbohydrate diet on blood glucose control in people with type 2 diabetes. Diabetes 53:2375-2382

18. Gannon MC, Nuttall FQ (2006) Control of blood glucose in type 2 diabetes without weight loss by modification of diet composition. Nutr Metab (Lond) 3:16

19. Nuttall FQ, Gannon MC (2006) The metabolic response to a highprotein, low-carbohydrate diet in men with type 2 diabetes mellitus. Metabolism 55:243-251

20. Nuttall FQ, Schweim K, Hoover H, Gannon MC (2008) Effect of the LoBAG30 diet on blood glucose control in people with type 2 diabetes. Br J Nutr 99:511-519 
21. Manders RJF, Wagenmakers AJM, Koopman R et al (2005) Coingestion of a protein hydrolysate and amino acid mixture with carbohydrate improves plasma glucose disposal in patients with type 2 diabetes. Am J Clin Nutr 82:76-83

22. Gannon MC, Nuttall FQ, Saeed A, Jordan K, Hoover H (2003) An increase in dietary protein improves the blood glucose response in persons with type 2 diabetes. Am J Clin Nutr 78:734-741

23. Nuttall FQ, Mooradian AD, Gannon MC, Billington C, Krezowski P (1984) Effect of protein ingestion on the glucose and insulin response to a standardized oral glucose load. Diab Care 7:465-470

24. Tremblay F, Brûlé S, Hee Um S et al (2007) Identification of IRS-1 Ser-1101 as a target of S6K1 in nutrient- and obesity-induced insulin resistance. Proc Natl Acad Sci 104:14056-14061

25. Patti ME, Brambilla E, Luzi L, Landaker EJ, Kahn CR (1998) Bidirectional modulation of insulin action by amino acids. J Clin Investig 101:1519-1529

26. World Health Organization (1995) Physical status: the use and interpretation of anthropometry. Report of a WHO Expert Committee. The Organization, Geneva

27. Chevalier S, Gougeon R, Kreisman SH, Cassis C, Morais JA (2004) The hyperinsulinemic amino acid clamp increases wholebody protein synthesis in young subjects. Metabolism 53:388-396

28. Sigal RJ, Purdon C, Fisher SJ, Halter JB, Vranic M, Marliss EB (1994) Hyperinsulinemia prevents prolonged hyperglycemia after intense exercise in insulin-dependent diabetic subjects. J Clin Endocrinol Metab 79:1049-1057

29. Bradley DC, Steil GM, Bergman RN (1993) Quantitation of measurement error with optimal segments: basis for adaptive time course smoothing. Am J Physiol 264:E902-911

30. Chevalier S, Marliss EB, Morais JA, Lamarche M, Gougeon R (2005) Whole-body protein anabolic response is resistant to the action of insulin in obese women. Am J Clin Nutr 82:355-365

31. Bradford MM (1976) A rapid and sensitive method for the quantitation of microgram quantities of protein utilizing the principle of protein-dye binding. Anal Biochem 72:248-254
32. Lachin JM (1981) Introduction to sample size determination and power analysis for clinical trials. Control Clin Trials 2:93-113

33. Esteghamati A, Ashraf H, Khalilzadeh O et al (2010) Optimal cutoff of homeostasis model assessment of insulin resistance (HOMA-IR) for the diagnosis of metabolic syndrome: third national surveillance of risk factors of non-communicable diseases in Iran (SuRFNCD-2007). Nutr Metab (Lond) 7:26

34. Mourad C, Chevalier S, Morais JA, Lamarche M, Gougeon R (2009) Antihyperglycaemic medication modifies factors of postprandial satiety in type 2 diabetes. Diabetes Obes Metab 11:819822

35. Muoio DM, Newgard CB (2008) Mechanisms of disease: molecular and metabolic mechanisms of insulin resistance and beta-cell failure in type 2 diabetes. Nat Rev Mol Cell Biol 9:193205

36. Gual P, Le Marchand-Brustel Y, Tanti J-F (2005) Positive and negative regulation of insulin signaling through IRS-1 phosphorylation. Biochimie 87:99-109

37. Frojdo S, Vidal H, Pirola L (2009) Alterations of insulin signaling in type 2 diabetes: a review of the current evidence from humans. Biochim Biophys Acta 1792:83-92

38. Bouzakri K, Roques M, Gual P et al (2003) Reduced activation of phosphatidylinositol-3 kinase and increased serine 636 phosphorylation of insulin receptor substrate-1 in primary culture of skeletal muscle cells from patients with type 2 diabetes. Diabetes 52:13191325

39. Hay N (2005) The Akt-mTOR tango and its relevance to cancer. Cancer Cell 8:179-183

40. Chevalier S, Marliss EB, Morais JA, Lamarche M, Gougeon R (2005) The influence of sex on the protein anabolic response to insulin. Metabolism 54:1529-1535

41. Bassil M, Marliss EB, Morais JA, Pereira S, Chevalier S, Gougeon R (2011) Postprandial hyperaminoacidaemia overcomes insulin resistance of protein anabolism in men with type 2 diabetes. Diabetologia 54:648-656 